\title{
Boosting Aerobic Oxidation of Alcohols via Synergistic Effect between TEMPO and a Composite $\mathrm{Fe}_{3} \mathrm{O}_{4} / \mathrm{Cu}-\mathrm{BDC} / \mathrm{GO}$ Nanocatalyst
}

Hassan Alamgholiloo, Sadegh Rostamnia,* Kaiqiang Zhang, Tae Hyung Lee, Yoon-Sik Lee, Rajender S. Varma,* Ho Won Jang,* and Mohammadreza Shokouhimehr*

Cite This: ACS Omega 2020, 5, 5182-5191

Read Online

ABSTRACT: Fabrication of a nanocomposite catalyst via a novel and efficient strategy remains a challenge; $\mathrm{Fe}_{3} \mathrm{O}_{4}$ nanoparticles anchored on graphene oxide (GO) sheet-supported metal-organic frameworks (MOFs). In this study, the physicochemical properties of the ensuing $\mathrm{Fe}_{3} \mathrm{O}_{4} / \mathrm{Cu}-\mathrm{BDC} / \mathrm{GO}$ are investigated using Fourier transform infrared spectrum, scanning electron microscopy, transmission electron microscopy, X-ray photoelectron spectroscopy, energy-dispersive X-ray detector, and atomic absorption spectroscopy. The salient features of the nanocomposite such as $\mathrm{Cu}-\mathrm{MOF}$, synergistic effect with GO sheets, and magnetic separation characteristics make it an excellent ternary heterostructure for aerobic oxidation of alcohols. The proposed nanocatalyst and co-catalyst 2,2,6,6-tetramethylpiperidine- $N$-oxyl substantially enhance the catalytic performance for the aerobic oxidation under very mild and sustainable reaction conditions. The heterogeneity of $\mathrm{Fe}_{3} \mathrm{O}_{4} / \mathrm{Cu}-\mathrm{BDC} / \mathrm{GO}$ composite catalyst is affirmed with the added advantage that the initial activity is well maintained even after seven cycles.

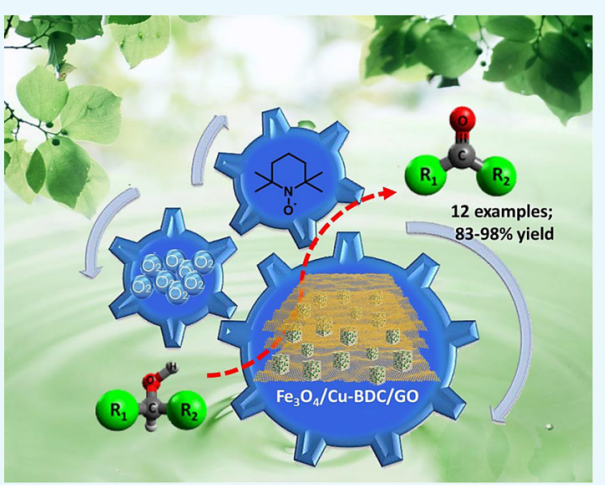

\section{INTRODUCTION}

The catalytic selective oxidation of alcohols to their corresponding carbonyl compounds is a vital and common transformation for the development of industrial organic chemistry. ${ }^{1,2}$ The increasing demand for clean synthesis has stimulated the development of efficient metal-free oxidation protocols. A family of stable nitroxide radicals, [2,2,6,6tetramethylpiperidine- $N$-oxyl] (TEMPO) and its derivatives, have garnered great interest owing to their high catalytic efficiency and chemoselectivity under environmentally friendly conditions; ${ }^{3}$ several TEMPO-catalyzed systems have displayed notable accomplishments. ${ }^{4}$ For example, Karimi's team developed the mesoporous materials such as SBA-15, ${ }^{5}$ MCM-41, and $\mathrm{PMO}^{7}$ as supports for TEMPO. Reiser et al. developed a highly efficient supported catalyst using click reaction to connect TEMPO radical to multiple perfluoroalkyl chains for the oxidation of alcohols. ${ }^{8}$ Wang and co-workers utilized the core/shell SPS-Cu' ${ }^{\mathrm{II}} @ \mathrm{Cu}-\mathrm{BTC}$ catalyst for the aerobic oxidation of alcohols by TEMPO. ${ }^{9}$ Recently, copper(II) complexes combined with TEMPO radicals ${ }^{10,11}$ have been proved to have an excellent catalytic performance for selective aerobic oxidation of alcohols. Besides this, benefitting from the potential catalytic sites offered by metal complexes and nanoparticles (NPs), the performance of heterogeneous catalysts could even outperform the corresponding homogeneous counterparts because of the synergetic effect. ${ }^{12,13}$ Although these methods can circumvent many disadvantages of homogeneous catalysis, typical problems such as a low immobilization capacity, metal leaching, poor catalytic activity and selectivity, etc. still persist. ${ }^{14,15}$

To attain high catalytic activity, nanostructuring catalysts with a porous character would be an essential way to expose accessible active sites. Metal-organic frameworks (MOFs) are a fascinating class of hybrid microporous materials with wellorganized structures, which have opened up new avenues for multifarious applications. ${ }^{16}$ In the field of composite nanoarchitecture, MOF/graphene oxide (GO) has emerged as a new class of catalytic composite materials due to their specific electrical and surface properties, excellent conductivity, and hydrophilic character; ${ }^{17-19}$ composite material developed by Bandosz's group ${ }^{20,21}$ has been found to be more stable and efficient. In addition, Cai and co-workers demonstrated a novel Europium-based MOFs [MIL-LIC-1(Eu)]/GO composite with application in aerobic oxidation of alcohols. ${ }^{22} \mathrm{We}$ have studied the catalytic application of GO-based nanocomposites containing NPs, such as Pd NPs-GO/P123, ${ }^{23}$ SE-Pd NPs/ $\mathrm{rGO}^{24}$ and Pd NPs-GO, ${ }^{25}$ as heterogeneous and recyclable green catalysts in organic transformations. However, the combination of open metal site MOFs (OMS-MOFs) with

Received: December 9, 2019

Accepted: February 5, 2020

Published: March 9, 2020 
Scheme 1. Synthetic Strategy for the Assembly of $\mathrm{Fe}_{3} \mathrm{O}_{4} / \mathrm{CuBDC} / \mathrm{GO}$

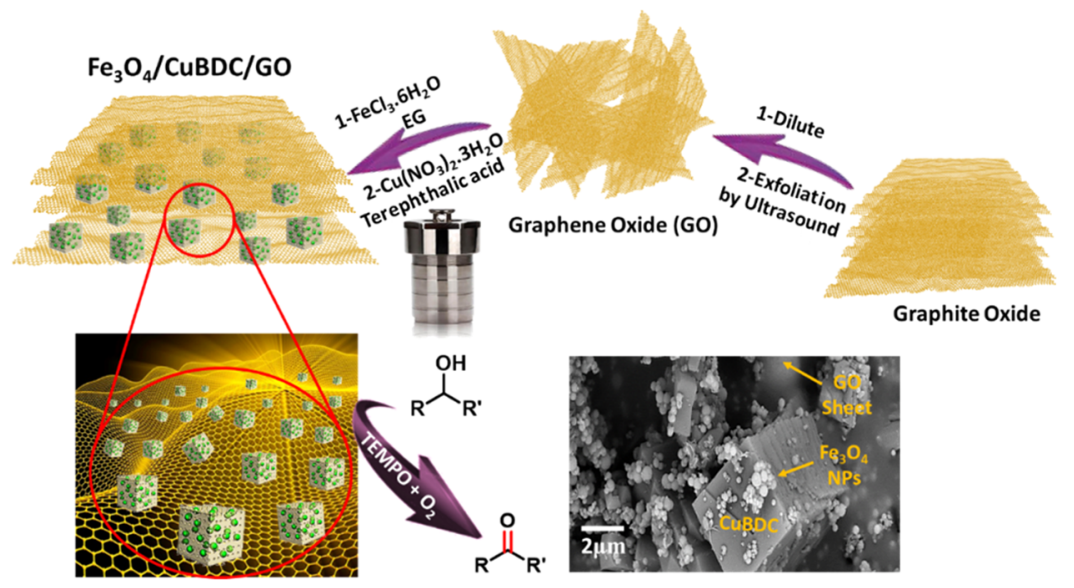

GO as a selective catalyst for aerobic oxidation of alcohols to carbonyls with TEMPO has not been explored. On the other hand, magnetic separation based on $\mathrm{Fe}_{3} \mathrm{O}_{4}$ NPs is widely utilized in catalytic application due to its economic earth abundance, convenience, and high efficiency. ${ }^{26-28}$

Motivated by the above considerations, herein, we describe a highly economic method for the fabrication of a ternary nanocomposite with $\mathrm{Fe}_{3} \mathrm{O}_{4} \mathrm{NPs}$ anchored on the open-metal site of a GO-sheet-supported $\mathrm{Cu}(\mathrm{BDC})$ composite $\left(\mathrm{Fe}_{3} \mathrm{O}_{4} /\right.$ $\mathrm{Cu}-\mathrm{BDC} / \mathrm{GO})$. Notably, the synergistic effect among the components ( $\mathrm{GO}$ sheets, $\mathrm{Fe}_{3} \mathrm{O}_{4} \mathrm{NPs}$, $\mathrm{Cu}-\mathrm{MOF}$, and TEMPO radical) has been studied during the selective oxidation of alcohols to their corresponding carbonyl compounds in the presence of molecular oxygen. Systematical studies on the catalytic activity of the proposed nanocomposite and TEMPO radicals toward a broad range of alcohols provided insights into the catalytic mechanism, particularly unraveling the synergistic effect between the nanocomposite components. To the best of our knowledge, this is the first example of the ternary nanocomposite exhibiting enhanced catalytic activity for aerobic oxidation of alcohols in the presence of TEMPO radicals boosted by copper centers from $\mathrm{Cu}-\mathrm{MOF}$.

\section{RESULTS AND DISCUSSION}

In a typical synthesis method, GO sheets were prepared by exfoliation of commercial graphite via dilution and sonication in aqueous media. The magnetic NPs and $\mathrm{Cu}-\mathrm{MOF}$ were grown simultaneously on GO sheets via a solvothermal method (Scheme 1). The salient advantages of the proposed

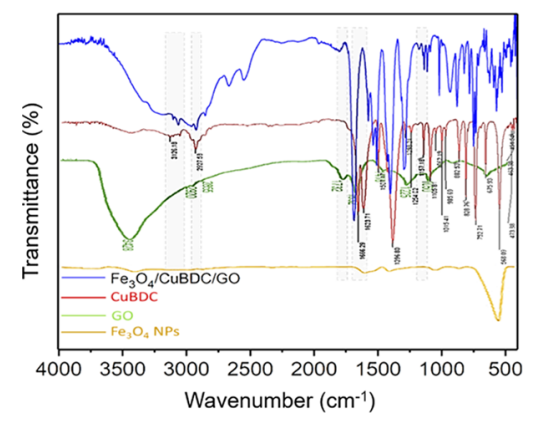

Figure 1. FT-IR spectra ternary nanocomposite (blue), CuBDC (red), GO (green), and $\mathrm{Fe}_{3} \mathrm{O}_{4}$ NPs (brown). catalyst are demonstrated in the aerobic oxidation of alcohols to aldehydes under base-free conditions.

Fourier transform infrared (FT-IR) analysis is utilized to explore the chemical structure of ternary nanocomposites (Figure 1). The spectra of CuBDC and those of the corresponding composite material exhibit high similarity. Asymmetric stretching is detected at wavenumbers of 1503$1666 \mathrm{~cm}^{-1}$ for the carboxylate groups in terephthalic acid and 1396 and $1623 \mathrm{~cm}^{-1}$ for the carboxylate groups in 1,4-benzene dicarboxylate $\left(\mathrm{H}_{2} \mathrm{BDC}\right)$. A variation of transmittance peaks of $\mathrm{Fe}_{3} \mathrm{O}_{4}, \mathrm{CuBDC}$, and $\mathrm{Fe}_{3} \mathrm{O}_{4} / \mathrm{OMS}-\mathrm{CuBDC} / \mathrm{GO}$ in a region of $2500-3800 \mathrm{~cm}^{-1}$ indicates the effect of the introduction of GO on the hybrid material.

The surficial chemical analysis is carried out using X-ray photoelectron spectra (XPS) (Figure 2). The characteristic peaks of $\mathrm{Fe} 2 \mathrm{p}, \mathrm{O} 1 \mathrm{~s}, \mathrm{Cu} 2 \mathrm{p}, \mathrm{C} 1 \mathrm{~s}$, and $\mathrm{N} 1 \mathrm{~s}$ in the spectrum demonstrate the presence of $\mathrm{Fe}_{3} \mathrm{O}_{4}, \mathrm{CuBDC}$, and $\mathrm{GO}$ sheets in $\mathrm{Fe}_{3} \mathrm{O}_{4} / \mathrm{OMS}-\mathrm{CuBDC} / \mathrm{GO}$ (Figure 2a). Three deconvoluted $\mathrm{C}$ 1 s peaks at $339.3,339.8$, and $342.2 \mathrm{eV}$ suggest that $\mathrm{sp}^{2}$ electron orbital-bonded carbon in carboxylate $(\mathrm{C}=\mathrm{C} / \mathrm{C}-\mathrm{C}),(\mathrm{N}-\mathrm{C}=$ $\mathrm{O})$ and $(\mathrm{O}-\mathrm{C}=\mathrm{O})$ is derived from terephthalic acid for CuBDC (Figure 2b). ${ }^{29}$ The deconvoluted O 1s spectra (Figure 2c) suggest $\mathrm{C}=\mathrm{O}(576.4 \mathrm{eV})$ and $\mathrm{C}-\mathrm{OH}(586.7 \mathrm{eV})$ bonds. A single peak at $392.1 \mathrm{eV}$ in the $\mathrm{N} 1 \mathrm{~s}$ spectrum indicates a characteristic value of $\mathrm{N}-\mathrm{C}$ originating from the solvent dimethylformamide (DMF) coordination in CuBDC (Figure $2 \mathrm{~d}$ ). Deconvoluted $\mathrm{Fe} 2 \mathrm{p}$ shows the binding energies at 610.4 $\left(2 \mathrm{p}_{3 / 2}\right)$ and $664.5 \mathrm{eV}\left(2 \mathrm{p}_{1 / 2}\right)$ in $\mathrm{Fe}_{3} \mathrm{O}_{4} \mathrm{NPs}$ (Figure 2e). The binding energy for $\mathrm{Cu}(\mathrm{II})$ is $918.6 \mathrm{eV}$, and the shift toward higher energy suggests a charge transfer from $\mathrm{Cu}$ (II) to organic ligands (Figure $2 \mathrm{f}$ ). ${ }^{30}$ Thus, these analyses confirm a successful decoration of $\mathrm{Fe}_{3} \mathrm{O}_{4} \mathrm{NPs}$ and $\mathrm{Cu}$-BDC MOF on GO sheets.

The crystalline structure of the prepared $\mathrm{Fe}_{3} \mathrm{O}_{4} / \mathrm{CuBDC} /$ $\mathrm{GO}$ was determined by an X-ray powder diffractometer as shown in Figure 3. The diffraction patterns of $\mathrm{Fe}_{3} \mathrm{O}_{4} / \mathrm{CuBDC} /$ GO are similar to those observed for $\mathrm{CuBDC}^{31}$ and $\mathrm{Fe}_{3} \mathrm{O}_{4}$ $\mathrm{NPs},{ }^{32}$ indicating the structural assemblies of $\mathrm{Cu}-\mathrm{MOF}$ and magnetic NPs. Although GO sheets cannot be observed in TEM images due to their monolayer form, all other peaks are consistent with the standard pattern of the parent materials. $^{33,34}$

The texture of the obtained ternary nanocomposite is investigated via field emission scanning electron microscopy (FE-SEM), and transmission electron microscopy (TEM; Figure 4). A cubic, layered morphology indicates a successful 
(a)

(c)
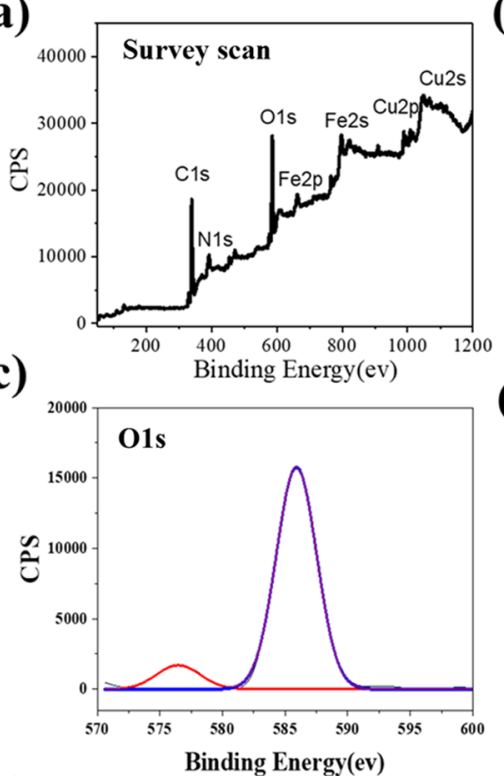

(e)

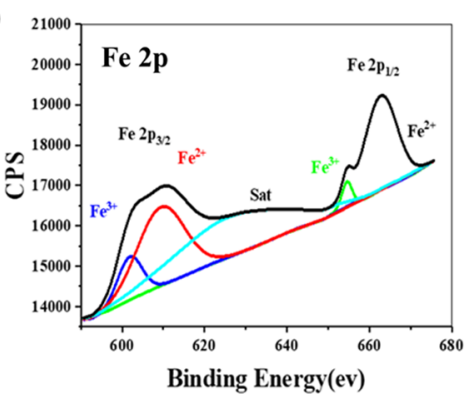

(b)

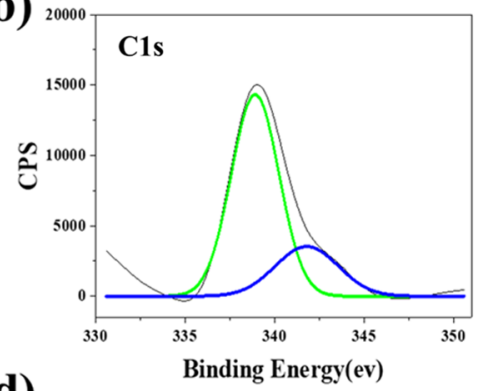

(d)

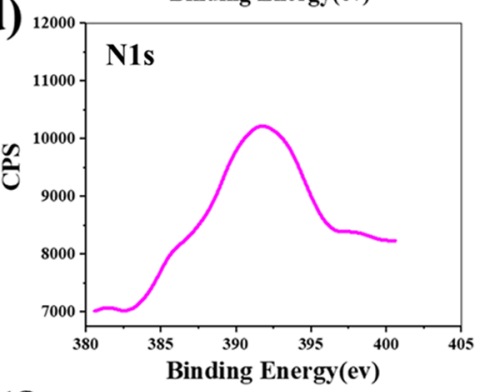

(f)

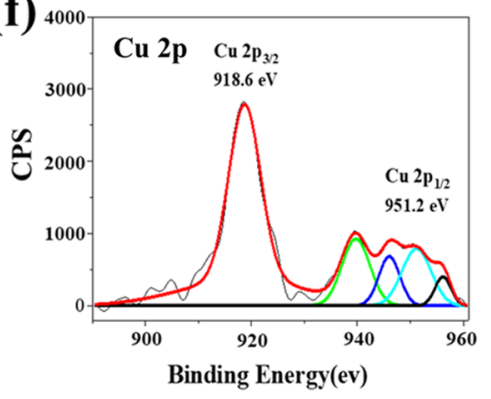

Figure 2. XPS spectra of the ternary nanocomposite: (a) wide survey scans; (b) C 1s; (c) O 1s; (d) N 1s; (e) Fe 2p; and (f) Cu 2p.

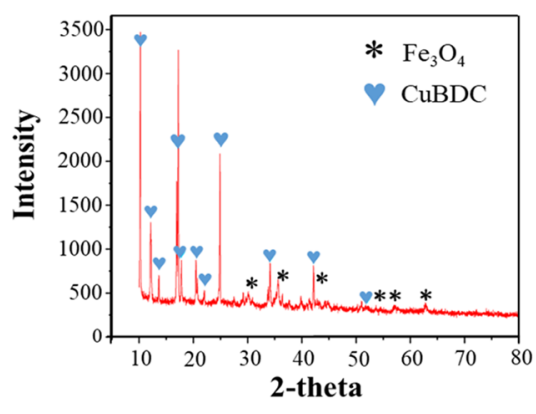

Figure 3. XRD pattern of $\mathrm{Fe}_{3} \mathrm{O}_{4} / \mathrm{CuBDC} / \mathrm{GO}$ nanocomposite.

formation of the OMS-CuBDC crystal ${ }^{35}$ in ternary nanocomposite (Figure 4b); $\mathrm{Fe}_{3} \mathrm{O}_{4} \mathrm{NPs}$ are heterogeneously dispersed on the $\mathrm{Cu}$-MOF surface as displayed in FE-SEM images. It should be noticed that the particle size of $\mathrm{Fe}_{3} \mathrm{O}_{4} /$ $\mathrm{CuBDC} / \mathrm{GO}$ composite is smaller than that of $\mathrm{CuBDC}$ without $\mathrm{Fe}_{3} \mathrm{O}_{4}$ NPs, which can be attributed to the $\mathrm{Fe}_{3} \mathrm{O}_{4}$ NPs acting as crystallization modulators and/or seeding materials for the formation of Cu-MOF crystals. ${ }^{36-38}$ The TEM analysis of the ternary nanocomposite clearly demonstrates the aggregated $\mathrm{Fe}_{3} \mathrm{O}_{4}$ particles. The result suggests that $\mathrm{Fe}_{3} \mathrm{O}_{4}$ particles remained essentially unchanged even after the conversion and integration process in CuBDC MOF.

Figure 4a shows a dark-field scanning TEM (STEM) micrograph of $\mathrm{Fe}_{3} \mathrm{O}_{4} / \mathrm{CuBDC} / \mathrm{GO}$, indicating a magnetic compound, MOF, and GO sheets. STEM energy-dispersive Xray (EDX) mapping images in Figure $5 \mathrm{~b}$ proved the presence of $\mathrm{C}, \mathrm{O}, \mathrm{Fe}$, and $\mathrm{Cu}$ elements in the ternary nanocomposite structure. In addition, the EDX mapping of $\mathrm{Fe}_{3} \mathrm{O}_{4} / \mathrm{CuBDC} /$ GO is depicted in Figure 5c, which affirms the high purity and incorporation of each component.

The superparamagnetic profile of the pure $\mathrm{Fe}_{3} \mathrm{O}_{4}$ and $\mathrm{Fe}_{3} \mathrm{O}_{4} / \mathrm{CuBDC} / \mathrm{GO}$ samples are measured by a vibrating sample magnetometer (VSM; Figure 6). The saturation magnetization value for ternary nanocomposite is $17.1 \mathrm{emu}$ $\mathrm{g}^{-1}$, which is lower than that of $\mathrm{Fe}_{3} \mathrm{O}_{4} \mathrm{NPs}\left(63.8 \mathrm{emu} \mathrm{g}{ }^{-1}\right)$ due to the introduction of $\mathrm{Cu}-\mathrm{MOF}$ and $\mathrm{GO}$ sheets; unlike $\mathrm{CuBDC}$ and GO, ternary nanocomposite illustrates small hysteresis loops, suggesting the incorporation of $\mathrm{Fe}_{3} \mathrm{O}_{4} \cdot{ }^{39,40}$ Thus, the ternary nanocomposite can be easily separated using an external magnet after the aerobic oxidation of alcohols.

An unexpected application of the ternary nanocomposite for the aerobic selective oxidation of alcohols under base-free conditions is studied. The optimization of experimental conditions is explored via oxidation of benzyl alcohol, as a model compound, with a TEMPO radical initiator where no reaction is observed in the absence of catalyst or TEMPO. Furthermore, a negligible conversion is attained for benzaldehyde in the absence of an $\mathrm{O}_{2}$ oxidant. Regarding the solvent effect, anaerobic oxidation of alcohols occurs in diverse solvents, namely, $\mathrm{CH}_{3} \mathrm{CN}, \mathrm{EtOH}, \mathrm{MeOH}, \mathrm{H}_{2} \mathrm{O}$, and toluene; the highest conversion (>98\%; Figure $7 \mathrm{a}$ ) is achieved using $\mathrm{CH}_{3} \mathrm{CN}$. Then, a quick survey of bases revealed that the conversion of alcohol without any base is similar to that using $\mathrm{K}_{2} \mathrm{CO}_{3}$, which indicates a highly efficient catalytic system (Figure $7 \mathrm{~b}$ ). Because the reactions at room temperature are 

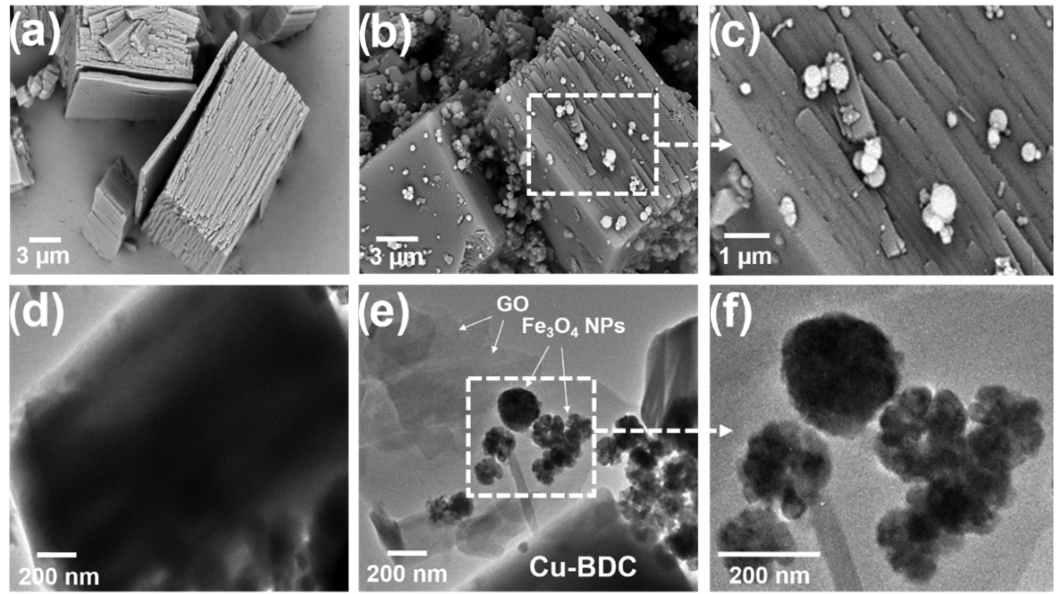

Figure 4. (a, d) FE-SEM and TEM images of CuBDC. (b, e) FE-SEM and TEM images of $\mathrm{Fe}_{3} \mathrm{O}_{4} / \mathrm{CuBDC} / \mathrm{GO}$. (c, f) FE-SEM and zoomed TEM images of $\mathrm{Fe}_{3} \mathrm{O}_{4} / \mathrm{CuBDC} / \mathrm{GO}$.
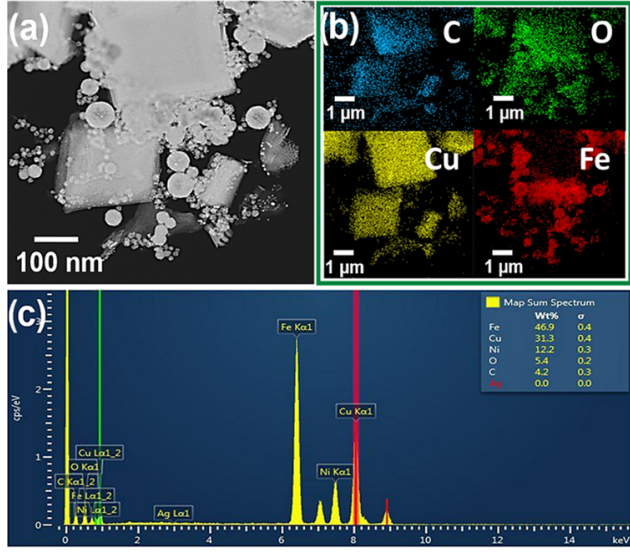

Figure 5. (a) STEM image, (b) STEM-EDX elemental mapping, and (c) EDX spectrum of $\mathrm{Fe}_{3} \mathrm{O}_{4} / \mathrm{CuBDC} / \mathrm{GO}$.

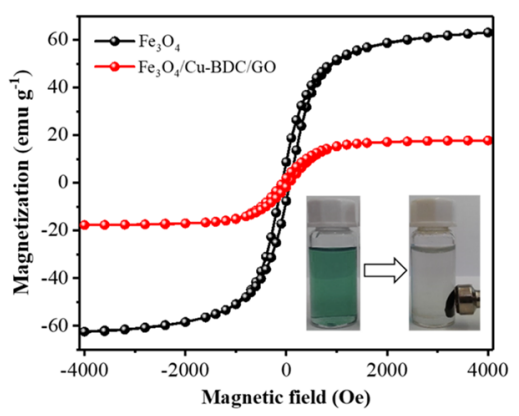

Figure 6. Magnetization curves of $\mathrm{Fe}_{3} \mathrm{O}_{4} / \mathrm{CuBDC} / \mathrm{GO}$ (red) and $\mathrm{Fe}_{3} \mathrm{O}_{4}$ (black) at room temperature.

equally effective and important from an energy consumption perspective, the studies are continued under ambient conditions (Figure $7 c, d$ ).

To investigate the catalytic activity of ternary nanocomposite, a series of controlled experiments are carried out (Figure 8a). Bare CuBDC, $\mathrm{Fe}_{3} \mathrm{O}_{4} \mathrm{NPs}$, and GO sheets results in a low product yield $(<60 \%)$ under optimized conditions. When $\mathrm{Fe}_{3} \mathrm{O}_{4} \mathrm{NPs}$ anchored on GO-sheet-supported $\mathrm{CuBDC}$ surface are deployed, they deliver benzaldehyde with more than $98 \%$ yield after $8 \mathrm{~h}$, demonstrating that the synergetic effect of $\mathrm{Fe}_{3} \mathrm{O}_{4} \mathrm{NPs}$ and $\mathrm{GO}$ sheets in $\mathrm{Fe}_{3} \mathrm{O}_{4} / \mathrm{CuBDC} / \mathrm{GO}$ plays a significant role. The highly improved catalytic activity is also comparable to that of a homogeneous catalyst, and $\mathrm{Cu}\left(\mathrm{NO}_{3}\right)_{2}$ shows the highest conversion ( $>75 \%$, Figure $\left.8 \mathrm{~b}\right)$. Notably, $\mathrm{Cu}\left(\mathrm{NO}_{3}\right)_{2}$, used for preparing OMS-CuBDC, exhibits higher catalytic activity than that of OMS-CuBDC but lower than that of $\mathrm{Fe}_{3} \mathrm{O}_{4} / \mathrm{OMS}-\mathrm{CuBDC} / \mathrm{GO}$.

To verify the synergetic effect of $\mathrm{Fe}_{3} \mathrm{O}_{4} \mathrm{NPs}$ and GO sheets on the stabilization of active $\mathrm{Cu}$ (II) interface in OMS-CuBDC framework, the oxidation of benzyl alcohol is explored. After each reaction cycle, the proposed catalyst is separated by a magnet and dried at $120{ }^{\circ} \mathrm{C}$ in vacuum, followed by reuse under the same reaction conditions. Figure 9 shows that $\mathrm{Fe}_{3} \mathrm{O}_{4} / \mathrm{CuBDC} / \mathrm{GO}$ remains substantially activity over seven cycles, with a conversion of $93.5 \%$ after the seventh cycle. The FE-SEM image of the catalyst after seven runs shows an intact structure, suggesting that the proposed nanocomposite is quite stable under optimized conditions (Figure 9b). After eight runs, the conversion of benzyl alcohol decreases from $91.5 \%$ (the seventh cycle) to $57.2 \%$ (the eighth cycle), with a selectivity of benzaldehyde over $94 \%$.

A controlled leaching experiment is performed to reach a deeper understanding of the heterogeneous nature of the proposed catalyst. The ICP-AES analysis of the aerobic oxidation of alcohols indicates negligible copper leaching (detection limit 2.1-3.5 ppm). Hot filtration test (Figure 10) of the reaction suspension to remove the insoluble $\mathrm{Fe}_{3} \mathrm{O}_{4}$ / $\mathrm{CuBDC} / \mathrm{GO}$ also led to the inhibition of homogeneous reaction. However, analysis of the mixture reaction illustrates that, after the removal of OMS-CuBDC catalyst, the yield of benzaldehyde increases from 15 to $37 \%$, indicating some copper leaching in the catalytic reaction. The results obtained from the leaching test suggest that the $\mathrm{GO}$ sheets and $\mathrm{Fe}_{3} \mathrm{O}_{4}$ NPs protect the heterogeneous catalyst from leaching to a certain degree as well as provide mass-transfer channels during the oxidation of alcohol reaction.

The subtract scope for the catalyst, $\mathrm{Fe}_{3} \mathrm{O}_{4} / \mathrm{CuBDC} / \mathrm{GO}$, with TEMPO as a co-catalyst is explored for the oxidation of alcohols under the optimized condition, and the results are summarized in Table 1. Primary benzylic alcohols (entries 19), either with an electron-withdrawing or an electrondonating substituent, afforded good conversion and excellent selectivity, except para- and meta-nitrobenzyl alcohols (entries 5 and 8 ), which resulted in 84 and $81 \%$ conversions, respectively. Moreover, the oxidation of secondary aliphatic and aromatic alcohols (entries 10-12) and the heteroatom- 
(a)

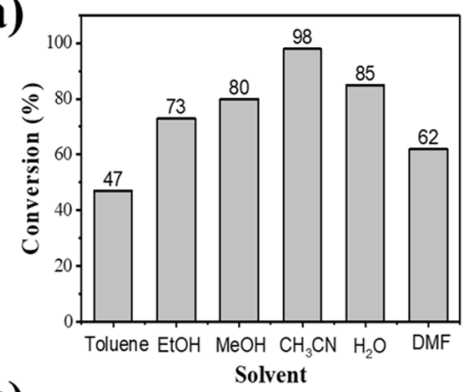

(c)

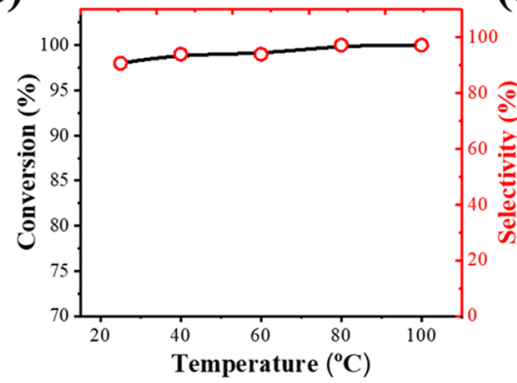

(b)

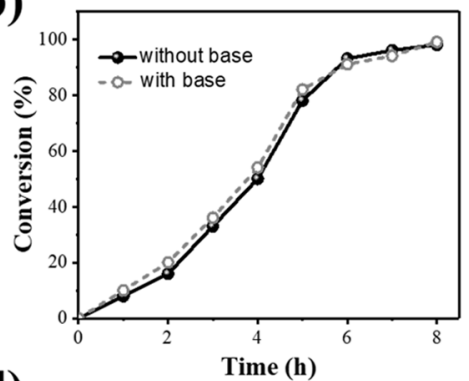

(d)

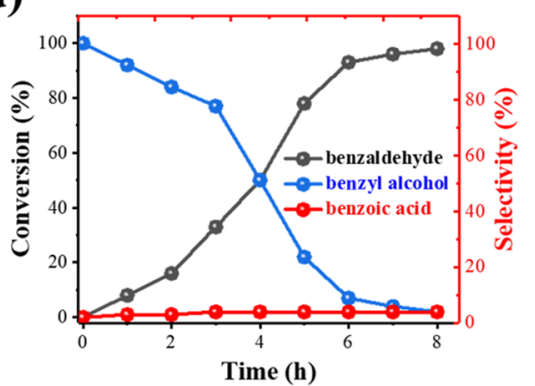

Figure 7. Effects of (a) solvent, (b) base, (c) temperature, and (d) kinetic on the aerobic oxidation of alcohols.

(a)

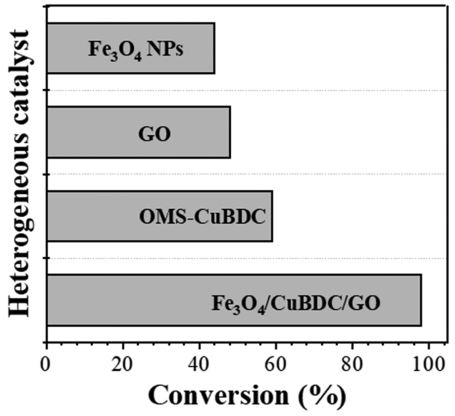

(b)

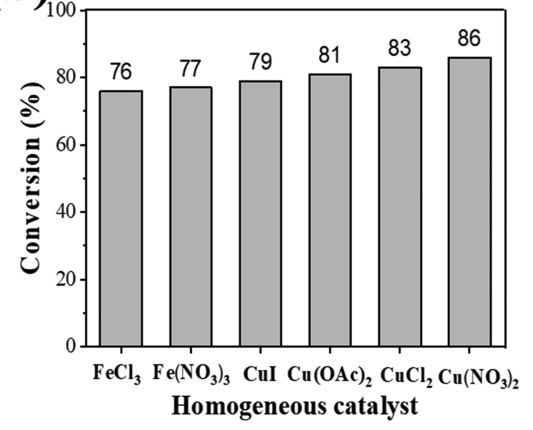

Figure 8. Effect of (a) heterogeneous and (b) homogeneous catalysts on the reaction proceeding in optimized conditions.

(a)

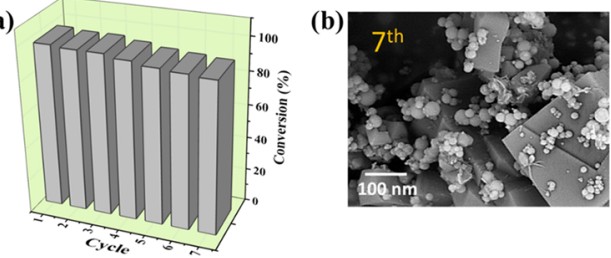

Figure 9. (a) Durability of the ternary catalyst in seven consecutive runs. (b) FE-SEM image of the catalyst after seven recycling cycles.

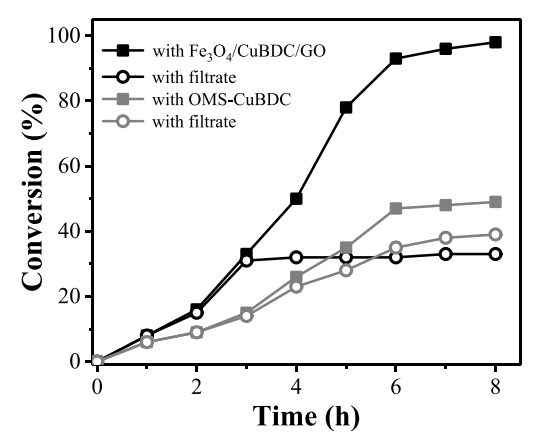

Figure 10. Kinetic of the reaction and the result of hot filtration test. substituted aromatic alcohols (entries 6 and 7) gave moderate yields, which was probably due to the steric interaction.

A comparative oxidative efficiency and catalytic activity of our catalyst, $\mathrm{Fe}_{3} \mathrm{O}_{4} / \mathrm{CuBDC} / \mathrm{GO}$, with several noble metals and noble transition metal (NTM) catalysts are presented in Table 2; the proposed catalyst exhibits higher conversion ratio and selectivity compared to those of other documented systems, with the exception of $\mathrm{Pd} @ \mathrm{MgO}^{41}$ and $\mathrm{Au}$ polystyrene. ${ }^{42}$ Notably, the better results are obtained using earth-abundant materials in our case.

The chemoselectivity and homoselectivity are also examined. Deploying an equimolar mixture of cyclohexane and benzyl alcohol with TEMPO in the presence of molecular oxygen under optimized conditions is used for the chemoselectivity study (Scheme 2a). An analysis of the mixture after $8 \mathrm{~h}$ indicates that the yield of benzaldehyde is $82 \%(1 \mathrm{a})$, whereas cyclohexanone is isolated in $11 \%$ yield (1b), with benzoic acid present only in trace amount (1c). The oxidation of 1,4bezenedimethanol in optimized conditions is selected for the test of homoselectivity of this method (Scheme 2b); both alcoholic groups are oxidized and terephthalic dialdehyde (2a) is produced in lower yield (39\%). By doubling the amount of all reactants, the yield of (2a) reaches a higher value of $76 \%$, whereas the formation of 4-hydroxymethyl benzaldehyde (2b) 
Table 1. Selective Oxidation of Various Alcohol Substrates Using $\mathrm{Fe}_{3} \mathrm{O}_{4} / \mathrm{CuBDC} / \mathrm{GO}^{a, b}$

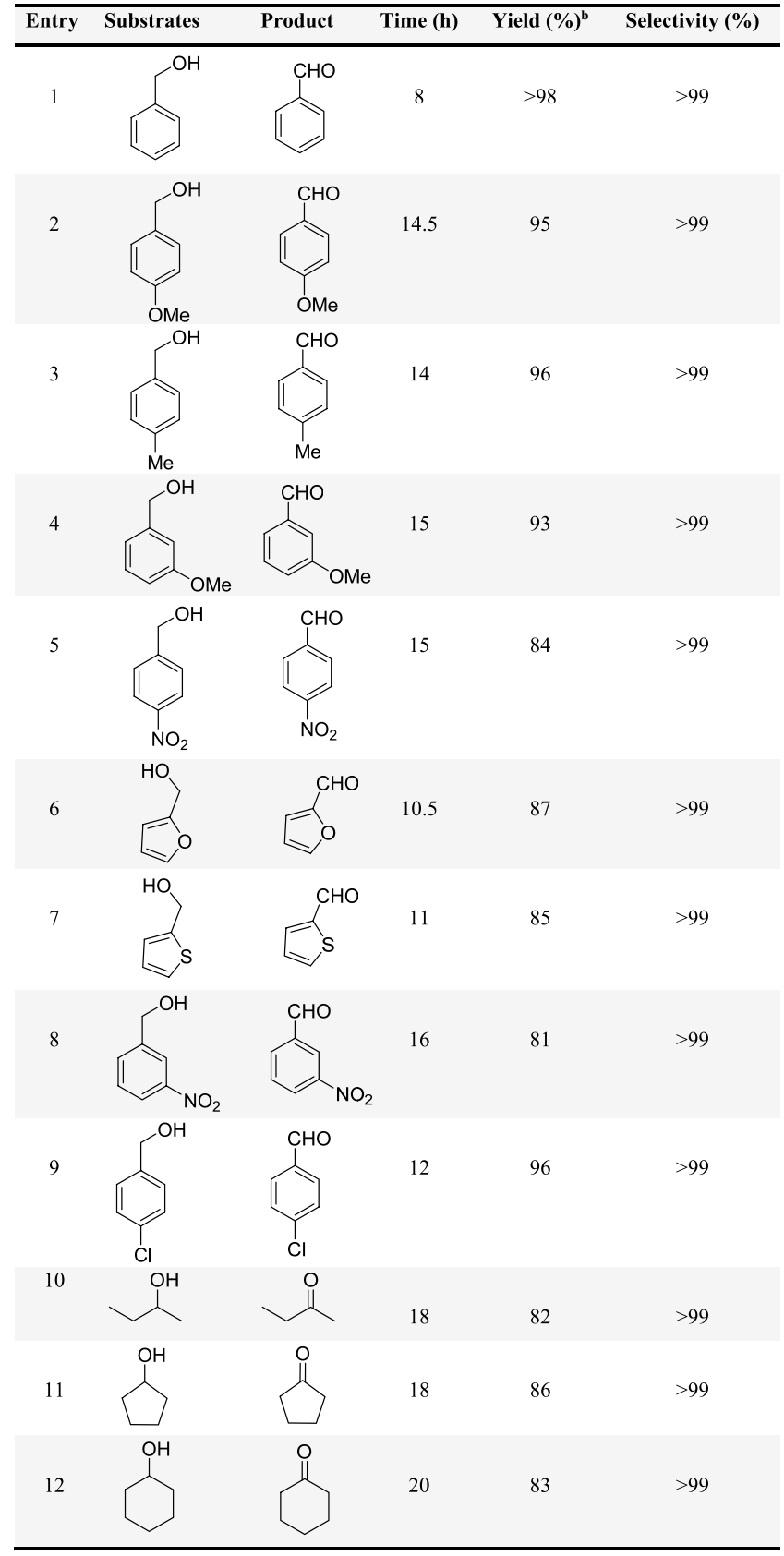

${ }^{a}$ Reaction conditions: alcohol ( $\left.1 \mathrm{mmol}\right), \mathrm{Fe}_{3} \mathrm{O}_{4} / \mathrm{CuBDC} / \mathrm{GO}(50$ $\mathrm{mg})$, TEMPO $(0.75 \mathrm{mmol})$, acetonitrile $(4 \mathrm{~mL}), 60{ }^{\circ} \mathrm{C}$, and 1 atom $\mathrm{O}_{2}$. ${ }^{b}$ Determined by gas chromatography (GC; Figure $\mathrm{S} 1$ ).

is negligible, suggesting this method is not appropriate for the homoselective aerobic oxidation of bifunctional alcohols.

Based on the aforementioned observations and the previously described mechanistic studies on the oxidation of alcohols, the plausible mechanism is depicted in Scheme 3, wherein copper-active sites in structure CuBDC and TEMPOH afford $\mathrm{Cu}^{\mathrm{II}}-\mathrm{OH}$ species and TEMPO.$^{58}$ This reaction sequence explains why strong bases, such as $\mathrm{KO}^{t} \mathrm{Bu}$ or $\mathrm{DBU}$, often deployed in such reactions, are not required when copper is used as a catalyst source; the base (MOF-Cu $\left.{ }^{\mathrm{II}}-\mathrm{OH}\right)$ is generated upon reduction of $\mathrm{O}_{2}{ }^{59-61}$ The oxidation of alcohol proceeds via the formation of a pre-equilibrium of
Scheme 2. Chemoselectivity and Homoselectivity of $\mathrm{Fe}_{3} \mathrm{O}_{4} /$ CuBDC/GO in Aerobic Oxidation of Alcohols

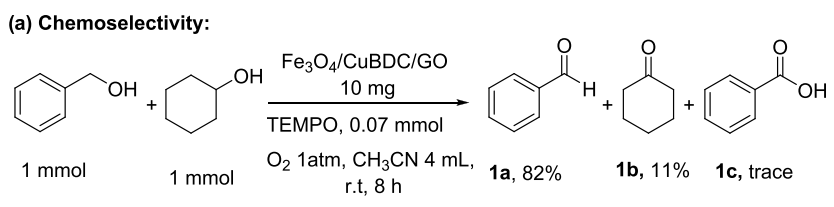

(b) Homoselectivity:

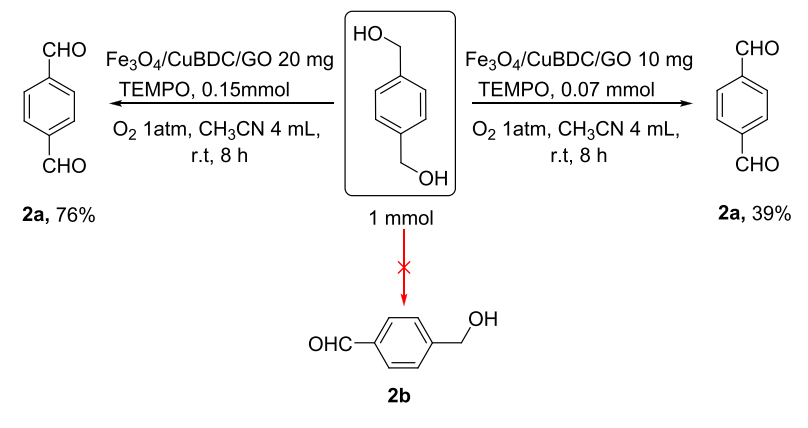

copper alkoxide species, followed by the transfer of $\mathrm{H}_{2}$ atom to TEMPO

\section{EXPERIMENTAL SECTION}

3.1. Materials and Instruments. Benzene 1,4-dicarboxylate $\left(\mathrm{H}_{2} \mathrm{BDC}\right), \mathrm{Cu}\left(\mathrm{NO}_{3}\right)_{2} \cdot 3 \mathrm{H}_{2} \mathrm{O}$, and other compounds and reagents were obtained commercially from Sigma-Aldrich, Merck (Germany), and Fluka (Switzerland), respectively. The ternary nanocomposite was characterized using powder X-ray diffraction (XRD) measurements (Philips-PW 1800 diffractometer). Scanning electron microscopy (SEM) images were recorded with a Hitachi S-4800 field emission scanning electron microscope. Transmission electron microscopy (TEM) and elemental mapping images were obtained using a JEOL JEM-2100F analytical electron microscope with an accelerating voltage of $200 \mathrm{kV}$. Fourier transform infrared (FTIR) spectra were obtained using a Shimadzu IR-640 spectrometer.

3.2. Synthesis of $\mathrm{Fe}_{3} \mathrm{O}_{4}$ NPs. The magnetic NPs were prepared according to the literature with some modifications. ${ }^{62}$ In a typical preparation, $1.35 \mathrm{~g}$ of $\mathrm{FeCl}_{3} \cdot 6 \mathrm{H}_{2} \mathrm{O}$ and $3.60 \mathrm{~g}$ of $\mathrm{NaOAc}$ were dissolved in $50 \mathrm{~mL}$ of ethylene glycol (EG), followed by stirring for $2 \mathrm{~h}$ with a magnetic bar. The obtained homogeneous grade yellow solution was treated in a Teflonlined autoclave in an oven at $473 \mathrm{~K}$ for $8 \mathrm{~h}$. Then, the Teflonlined autoclave was cooled slowly at a rate $1{ }^{\circ} \mathrm{C} \min ^{-1}$ to ambient temperature. The obtained black precipitation was washed with ethanol and deionized water (DI) water for three times and then dried at $70{ }^{\circ} \mathrm{C}$ overnight.

3.3. Fabrication of OMS-CuBDC. $\mathrm{Cu}(\mathrm{BDC})^{\bullet} n \mathrm{DMF}$ was synthesized based on a previously reported method with slight modifications. ${ }^{35,63}$ In a typical preparation, $1.812 \mathrm{~g}$ of copper nitrate trihydrate, $1.24 \mathrm{~g}$ of terephthalic acid, and $1 \mathrm{mmol}$ of $\mathrm{Et}_{3} \mathrm{~N}$ for deprotonate terephthalic acid were dissolved in 150 $\mathrm{mL}$ of DMF. The obtained homogeneous blue solution was placed in a Teflon-lined autoclave and heated at $110^{\circ} \mathrm{C}$ for 36 h. Thereafter, the blue precipitation was collected by centrifugation and washed three times with DMF and methanol to remove organic species trapped within pores. Finally, $\mathrm{Cu}(\mathrm{BDC}) \cdot n \mathrm{DMF}$ was activated at $140{ }^{\circ} \mathrm{C}$ in a vacuum to obtain open metal sites to afford a $69 \%$ yield of OMS$\mathrm{Cu}(\mathrm{BDC}) \mathrm{MOF}$. 
Table 2. Summary of Reaction Conditions and Results for Oxidation of Alcohols in the Presence of Oxygen Molecular ${ }^{41-57}$

\begin{tabular}{|c|c|c|c|c|c|c|}
\hline Catalyst & Support & Solvent & $\begin{array}{c}\text { T }\left({ }^{\circ} \mathrm{C}\right) / \\
\mathbf{t}(\mathbf{h})\end{array}$ & $\begin{array}{c}\text { Conv. } \\
(\%)\end{array}$ & $\begin{array}{c}\text { Select } \\
(\%)\end{array}$ & Ref. \\
\hline$\overline{P d}$ & Silica-alumina & Solvent free & $80 / 24$ & $>99$ & $>99$ & 43 \\
\hline $\mathrm{Pd}$ & $\gamma-\mathrm{Al}_{2} \mathrm{O}_{3}$ & Solvent free & $90 / 8$ & 97 & 96 & 44 \\
\hline $\mathrm{Pd}$ & $\mathrm{MgO}$ & Solvent free & $45 / 7$ & 100 & 99 & 41 \\
\hline Pd & - & Acetic acid & $60 / 14$ & 95 & 92 & 45 \\
\hline $\mathrm{Pd}$ & $\mathrm{Cu}^{\mathrm{II}}-\mathrm{MOFs}$ & Xylene & $130 / 25$ & 95 & 99 & 46 \\
\hline $\mathrm{Pd}$ & $\mathrm{MnCeOx}$ & Solvent free & $80 / 24$ & 18.4 & 98.6 & 47 \\
\hline $\mathrm{Pt}$ & Activated carbon & Water & $80 / 3$ & 50 & 80 & 48 \\
\hline $\mathrm{Pt}$ & MOF-177 & Solvent free & $25 / 24$ & 50 & $>99$ & 49 \\
\hline $\mathrm{Au}$ & $\mathrm{TiO}_{2}$ & Solvent free & $160 / 6$ & 55.0 & 73.7 & 50 \\
\hline $\mathrm{Au}$ & Hydrotalcite & Toluene & $40 / 24$ & 85.0 & 91.7 & 51 \\
\hline $\mathrm{Au}$ & polystyrene & $\mathrm{BTF}^{\mathrm{b}} / \mathrm{H}_{2} \mathrm{O}$ & $25 / 5$ & $75-99$ & 99 & 42 \\
\hline $\mathrm{Ru}$ & $\mathrm{Al}_{2} \mathrm{O}_{3}$ & Trifluorotoluene & $85 / 1$ & 99 & $>99$ & 52 \\
\hline $\mathrm{Ru}$ & MOF-253(Al) & $\mathrm{CH}_{2} \mathrm{Cl}_{2}$ & $40 / 3$ & 97 & $>99$ & 53 \\
\hline $\mathrm{MnO}_{2}$ & $\gamma-\mathrm{Al}_{2} \mathrm{O}_{3}$ & Toluene & $100 / 3$ & 72.9 & $>99$ & 54 \\
\hline $\mathrm{Mo}_{\mathrm{x}} \mathrm{V}_{\mathrm{y}} \mathrm{O}_{\mathrm{z}}$ & - & Toluene & $80 / 24$ & 22 & $>99$ & 55 \\
\hline $\mathrm{Cu}$ & MOF-74 & $\mathrm{CH}_{3} \mathrm{CN}$, DMAP & $70 / 12$ & 89 & $>99$ & 56 \\
\hline $\mathrm{Cu}$ & UiO-66-Sal & $\begin{array}{l}\mathrm{CH}_{3} \mathrm{CN}, \\
\mathrm{NaHCO}_{3}\end{array}$ & $60 / 24$ & 99 & 99 & 57 \\
\hline $\mathrm{Cu}$ & $\mathrm{MOF} / \mathrm{Fe}_{3} \mathrm{O}_{4} / \mathrm{GO}$ & $\mathrm{CH}_{3} \mathrm{CN}$ & $25 / 8$ & 98 & $>99$ & This study \\
\hline
\end{tabular}

Scheme 3. Possible Oxidation Mechanism for Alcohols Using $\mathrm{Fe}_{3} \mathrm{O}_{4} / \mathrm{CuBDC} / \mathrm{GO}$

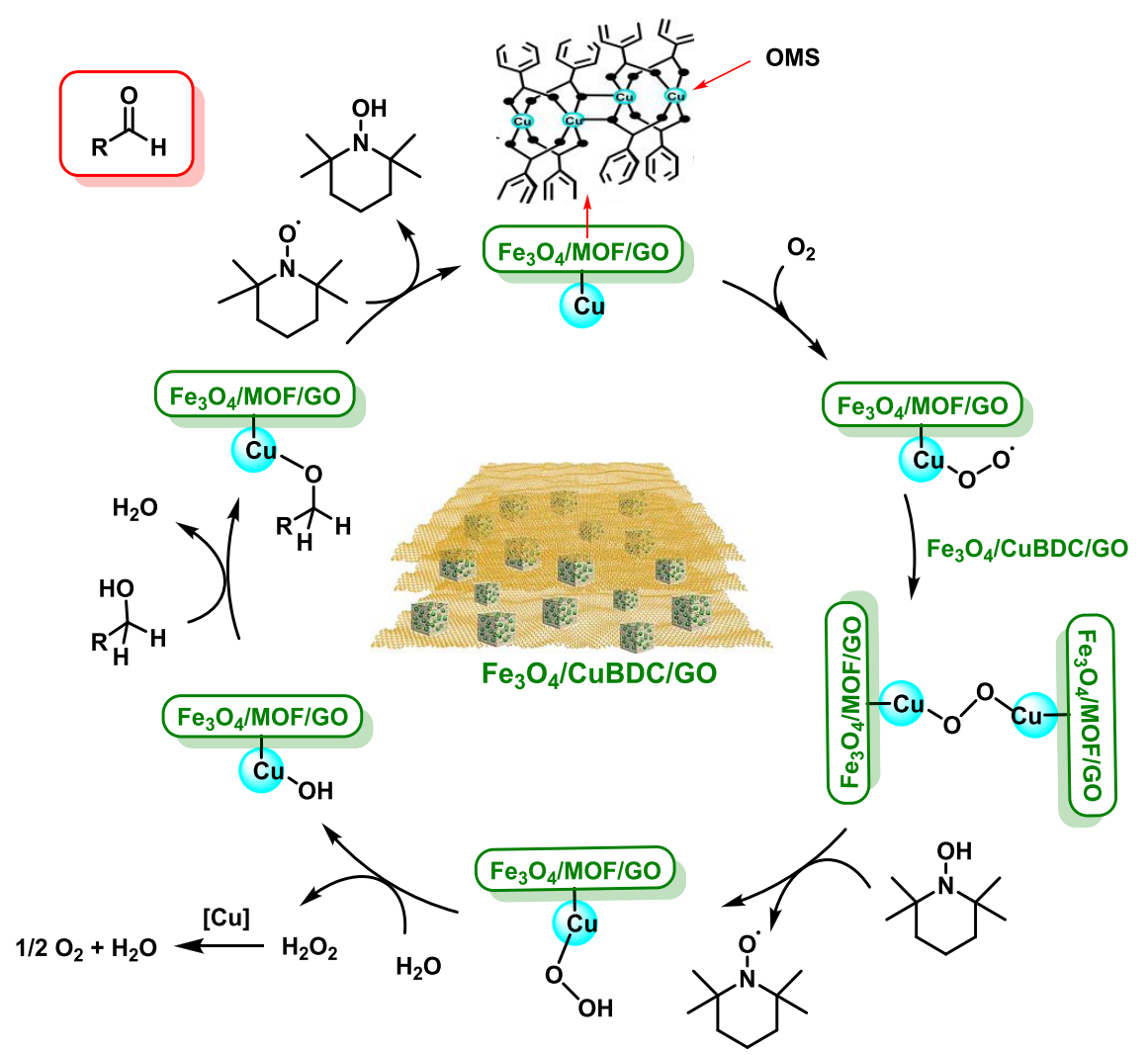

3.4. Fabrication of $\mathrm{Fe}_{3} \mathrm{O}_{4} / \mathrm{CuBDC} / \mathrm{GO}$. $\mathrm{Fe}_{3} \mathrm{O}_{4} / \mathrm{OMS}$ $\mathrm{Cu}(\mathrm{BDC})$ was prepared by a solvothermal method. GO was prepared by the oxidation of graphite according to the
Hummer method. ${ }^{64}$ A suspension of $0.1 \mathrm{mg} / \mathrm{mL}$ GO in EG solvent was prepared via vigorous sonication for $120 \mathrm{~min}$ under ambient conditions. Then, equimolar of copper nitrate 
trihydrate (7.5 mmol, $1.812 \mathrm{~g})$ and terephthalic acid (7.5 mmol, $1.245 \mathrm{~g}$ ) were dissolved in $150 \mathrm{~mL}$ of DMF. The mixture was stirred for $30 \mathrm{~min}$, followed by the introduction of $0.25 \mathrm{~g}$ of $\mathrm{Fe}_{3} \mathrm{O}_{4}$. The mixture was transferred to a Teflon-lined autoclave and heated in an oven at $110{ }^{\circ} \mathrm{C}$ for $36 \mathrm{~h}$. Afterward, the Teflon-lined autoclave was cooled slowly at a rate of $1{ }^{\circ} \mathrm{C}$ $\mathrm{min}^{-1}$ to room temperature; the ensuing green powder was filtered off, washed several times with DMF and dichloromethane, and then dried overnight at $393 \mathrm{~K}$ in vacuum. The wt $\%$ of copper in $\mathrm{Fe}_{3} \mathrm{O}_{4} / \mathrm{CuBDC} / \mathrm{GO}$ measured with AAS was found to be $31.3 \%$.

3.5. Catalytic Reaction. The selective oxidation of alcohols was conducted in a $25 \mathrm{~mL}$ flask fitted with a reflux condenser. Typically, certain amounts of catalyst, alcohol (1 $\mathrm{mmol})$, and TEMPO $(0.75 \mathrm{mmol})$ were added to $4 \mathrm{~mL}$ of acetonitrile. This system was purged two times with oxygen $\left(\mathrm{O}_{2}\right)$ and then sealed with an $\mathrm{O}_{2}$ balloon. The reaction mixture was heated to the desired reaction temperature under constant stirring. After completing the reaction, the catalysts were removed from the solution with a simple magnet; the liquid organic products were analyzed by gas chromatography-mass spectrometry (GC-MS). After each cycle of catalytic reaction, the catalysts were collected using an external magnet and dried at $100{ }^{\circ} \mathrm{C}$ in a vacuum for subsequent reuse.

\section{CONCLUSIONS}

In summary, a novel ternary hybrid nanomaterial with a controllable active copper(II) interface is fabricated via a facile method under mild synthetic conditions. Magnetic nanoparticles with open metal site CuBDC MOF were grown simultaneously on GO sheets. The active copper in OMS$\mathrm{CuBDC}$ frameworks and the synergistic interaction between GO and $\mathrm{Fe}_{3} \mathrm{O}_{4}$ NPs make the hybrid nanocomposite an excellent catalyst with high efficiency and reusability for the aerobic oxidation of alcohols to aldehydes. Therefore, the controllable design of $\mathrm{Fe}_{3} \mathrm{O}_{4} / \mathrm{CuBDC} / \mathrm{GO}$ structure using earth-abundant materials may provide an innovative approach for the exploration of highly active and stable heterogeneous catalysts for diverse catalytic applications.

\section{ASSOCIATED CONTENT}

\section{SI Supporting Information}

The Supporting Information is available free of charge at https://pubs.acs.org/doi/10.1021/acsomega.9b04209.

Gas chromatography (GC) result (PDF)

\section{AUTHOR INFORMATION}

\section{Corresponding Authors}

Sadegh Rostamnia - Organic and Nano Group (ONG), Department of Chemistry, Faculty of Science, University of Maragheh, Maragheh 55181-83111, Iran; 이이.org/00000001-6310-8754; Email: rostamnia@maragheh.ac.ir

Rajender S. Varma - Regional Centre of Advanced Technologies and Materials, Department of Physical Chemistry, Faculty of Science, Palacky University, Olomouc 783 71, Czech Republic; ๑ orcid.org/0000-0001-9731-6228; Email: varma.rajender@ epa.gov

Ho Won Jang - Department of Materials Science and Engineering, Research Institute of Advanced Materials, Seoul National University, Seoul 08826, Republic of Korea; 이이.org/0000-0002-6952-7359; Email: hwjang@ snu.ac.kr
Mohammadreza Shokouhimehr - Department of Materials Science and Engineering, Research Institute of Advanced Materials, Seoul National University, Seoul 08826, Republic of Korea; ㅇo orcid.org/0000-0003-1416-6805; Email: mrsh2@ snu.ac.kr

\section{Authors}

Hassan Alamgholiloo - Organic and Nano Group (ONG), Department of Chemistry, Faculty of Science, University of Maragheh, Maragheh 55181-83111, Iran

Kaiqiang Zhang - Department of Materials Science and Engineering, Research Institute of Advanced Materials, Seoul National University, Seoul 08826, Republic of Korea

Tae Hyung Lee - Department of Materials Science and Engineering, Research Institute of Advanced Materials, Seoul National University, Seoul 08826, Republic of Korea

Yoon-Sik Lee - Department of Chemical and Biological Engineering, Seoul National University, Seoul 08826, Republic of Korea

Complete contact information is available at:

https://pubs.acs.org/10.1021/acsomega.9b04209

\section{Notes}

The authors declare no competing financial interest.

\section{ACKNOWLEDGMENTS}

This research was supported by the Future Material Discovery Program (2016M3D1A1027666), the Basic Science Research Program (2017R1A2B3009135) through the National Research Foundation of Korea, and the China Scholarship Council (201808260042).

\section{REFERENCES}

(1) Zhang, K.; Suh, J. M.; Choi, J. W.; Jang, H. W.; Shokouhimehr, M.; Varma, R. S. Recent Advances in the Nanocatalyst-Assisted $\mathrm{NaBH}_{4}$ Reduction of Nitroaromatics in Water. ACS Omega 2019, 4, 483-495.

(2) Zhuang, J. L.; Liu, X. Y.; Zhang, Y.; Wang, C.; Mao, H. L.; Guo, J.; Terfort, A. Zr-Metal-Organic Frameworks Featuring TEMPO Radicals: Synergistic Effect between TEMPO and Hydrophilic ZrNode Defects Boosting Aerobic Oxidation of Alcohols. ACS Appl. Mater. Interfaces 2019, 11, 3034-3043.

(3) Wertz, S.; Studer, A. Nitroxide-Catalyzed Transition-Metal-Free Aerobic Oxidation Processes. Green Chem. 2013, 15, 3116-3134.

(4) Ryland, B. L.; Stahl, S. S. Practical Aerobic Oxidations of Alcohols and Amines with Homogeneous Copper/TEMPO and Related Catalyst Systems. Angew. Chem., Int. Ed. 2014, 53, 88248838.

(5) Karimi, B.; Biglari, A.; Clark, J. H.; Budarin, V. Green, Transition-Metal-Free Aerobic Oxidation of Alcohols Using a Highly Durable Supported Organocatalyst. Angew. Chem., Int. Ed. 2007, 46, $7210-7213$

(6) Karimi, B.; Rafiee, M.; Alizadeh, S.; Vali, H. Eco-Friendly Electrocatalytic Oxidation of Alcohols on a Novel Electro Generated TEMPO-Functionalized MCM-41 Modified Electrode. Green Chem. 2015, 17, 991-1000.

(7) Karimi, B.; Vahdati, S.; Vali, H. Synergistic Catalysis within TEMPO-Functionalized Periodic Mesoporous Organosilica with Bridge Imidazolium Groups in the Aerobic Oxidation of Alcohols. RSC Adv. 2016, 6, 63717-63723.

(8) Gheorghe, A.; Chinnusamy, T.; Cuevas-Yañez, E.; Hilgers, P.; Reiser, O. Combination of Perfluoroalkyl and Triazole Moieties: A New Recovery Strategy for TEMPO. Org. Lett. 2008, 10, 4171-4174.

(9) Zhang, X.; Dong, W.; Luan, Y.; Yang, M.; Tan, L.; Guo, Y.; Gao, H.; Tang, Y.; Dang, R.; Li, J.; Wang, G. Highly Efficient SulfonatedPolystyrene-Cu(II)@Cu ${ }_{3}(\mathrm{BTC})_{2}$ Core-Shell Microsphere Catalysts 
for Base-Free Aerobic Oxidation of Alcohols. J. Mater. Chem. A 2015, 3, 4266-4273.

(10) Kumpulainen, E. T.; Koskinen, A. M. Catalytic Activity Dependency on Catalyst Components in Aerobic Copper-TEMPO Oxidation. Chem. - Eur. J. 2009, 15, 10901-10911.

(11) Tu, B.; Pang, Q.; Xu, H.; Li, X.; Wang, Y.; Ma, Z.; Weng, L.; Li, Q. Reversible Redox Activity in Multicomponent Metal-Organic Frameworks Constructed from Trinuclear Copper Pyrazolate Building Blocks. J. Am. Chem. Soc. 2017, 139, 7998-8007.

(12) McGuirk, C. M.; Katz, M. J.; Stern, C. L.; Sarjeant, A. A.; Hupp, J. T.; Farha, O. K.; Mirkin, C. A. Turning on Catalysis: Incorporation of a Hydrogen-Bond-Donating Squaramide Moiety into a $\mathrm{Zr}$ MetalOrganic Framework. J. Am. Chem. Soc. 2015, 137, 919-925.

(13) Možina, S.; Iskra, J. Aerobic Oxidation of Secondary Alcohols with Nitric Acid and Iron (III) Chloride as Catalysts in Fluorinated Alcohol. J. Org. Chem. 2019, 84, 14579-14586.

(14) Shokouhimehr, M.; Mahmoudi Gom-Yek, S.; Nasrollahzadeh, M.; Kim, A.; Varma, R. S. Palladium Nanocatalysts on Hydroxyapatite: Green Oxidation of Alcohols and Reduction of Nitroarenes in Water. Appl. Sci. 2019, 9, 4183.

(15) Ahadi, A.; Alamgholiloo, H.; Rostamnia, S.; Liu, Z.; Shokouhimehr, M.; Alonso, D. A.; Luque, R. Layer-wise Titania Growth within Dimeric Organic Functional Group Viologenperiodic Mesoporous Organosilica as Efficient Photocatalyst for Oxidative Formic Acid Decomposition. ChemCatChem 2019, 11, 4803.

(16) Zhang, K.; Lee, T. H.; Noh, H.; Farha, O. K.; Jang, H. W.; Choi, J. W.; Shokouhimehr, M. Tailorable Topologies for Selectively Controlling Crystals of Expanded Prussian Blue Analogs. Cryst. Growth Des. 2019, 19, 7385-7395.

(17) Li, L.; Liu, X. L.; Gao, M.; Hong, W.; Liu, G. Z.; Fan, L.; Hu, B.; Xia, Q. H.; Liu, L.; Song, G. W.; Xu, Z. S. The Adsorption on Magnetic Hybrid $\mathrm{Fe}_{3} \mathrm{O}_{4}$ /HKUST-1/GO of Methylene Blue from Water Solution. J. Mater. Chem. A 2014, 2, 1795-1801.

(18) Zhang, Y.; Li, G.; Lu, H.; Lv, Q.; Sun, Z. Synthesis, Characterization and Photocatalytic Properties of MIL-53(Fe)Graphene Hybrid Materials. RSC Adv. 2014, 4, 7594-7600.

(19) Wu, Y.; Luo, H.; Wang, H. Synthesis of Iron (III)-Based Metal-Organic Framework/Graphene Oxide Composites with Increased Photocatalytic Performance for Dye Degradation. RSC Adv. 2014, 4, 40435-40438.

(20) Petit, C.; Bandosz, T. J. MOF-Graphite Oxide Composites: Combining the Uniqueness of Graphene Layers and Metal-Organic Frameworks. Adv. Mater. 2009, 21, 4753-4757.

(21) Petit, C.; Bandosz, T. J. MOF-Graphite Oxide Nanocomposites: Surface Characterization and Evaluation as Adsorbents of Ammonia. J. Mater. Chem. 2009, 19, 6521-6528.

(22) Cai, J.; Lu, J.-Y.; Chen, Q.-Y.; Qu, L.-L.; Lu, Y.-Q.; Gao, G.-F. Eu-Based MOF/Graphene Oxide Composite: A Novel Photocatalyst for the Oxidation of Benzyl Alcohol Using Water as Oxygen Source. New J. Chem. 2017, 41, 3882-3886.

(23) Rostamnia, S.; Doustkhah, E.; Karimi, Z.; Amini, S.; Luque, R. Surfactant-Exfoliated Highly Dispersive Pd-Supported Graphene Oxide Nanocomposite as a Catalyst for Aerobic Aqueous Oxidations of Alcohols. Chem CatChem 2015, 7, 1678-1683.

(24) Rostamnia, S.; Doustkhah, E.; Zeynizadeh, B. Exfoliation Effect of PEG-Type Surfactant on Pd Supported GO (SE-Pd (nanoparticle)/GO) in Cascade Synthesis of Amides: A Comparison with Pd (nanoparticle)/rGO. J. Mol. Catal. A: Chem. 2016, 416, 88-95.

(25) Rostamnia, S.; Zeynizadeh, B.; Doustkhah, E.; Hosseini, H. G. Exfoliated Pd Decorated Graphene Oxide Nanosheets (PdNP-GO/ P123): Non-Toxic, Ligandless and Recyclable in Greener Hiyama Cross-Coupling Reaction. J. Colloid Interface Sci. 2015, 451, 46-52.

(26) Gawande, M. B.; Branco, P. S.; Varma, R. S. Nano-Magnetite $\left(\mathrm{Fe}_{3} \mathrm{O}_{4}\right)$ as A Support for Recyclable Catalysts in the Development of Sustainable Methodologies. Chem. Soc. Rev. 2013, 42, 3371-3393.

(27) Shokouhimehr, M. Magnetically Separable and Sustainable Nanostructured Catalysts for Heterogeneous Reduction of Nitroaromatics. Catalysts 2015, 5, 534-560.
(28) Nasir Baig, R. B.; Varma, R. S. Organic Synthesis via Magnetic Attraction: Benign and Sustainable Protocols Using Magnetic Nanoferrites. Green Chem. 2013, 15, 398-417.

(29) Rong, M.; Lin, L.; Song, X.; Zhao, T.; Zhong, Y.; Yan, J.; Wang, Y.; Chen, X. A Label-Free Fluorescence Sensing Approach for Selective and Sensitive Detection of 2,4,6-Trinitrophenol (TNP) in Aqueous Solution Using Graphitic Carbon Nitride Nanosheets. Anal. Chem. 2015, 87, 1288-1296.

(30) Chen, X. Y.; Chen, C.; Zhang, Z. J.; Xie, D. H. Gelatin-Derived Nitrogen-Doped Porous Carbon via A Dual-Template Carbonization Method for High Performance Supercapacitors. J. Mater. Chem. A 2013, 1, 10903-10911.

(31) Li, Z.; Xia, H.; Li, S.; Pang, J.; Zhu, W.; Jiang, Y. In situ Hybridization of Enzymes and their Metal-Organic Framework Analogues with Enhanced Activity and Stability by Biomimetic Mineralisation. Nanoscale 2017, 9, 15298-15302.

(32) Wu, L.; Yang, C.; Lv, Z.; Cui, F.; Zhao, L.; Yang, P. Facile OnePot Synthesis of Different Surfactant-Functionalized Water-Soluble $\mathrm{Fe}_{3} \mathrm{O}_{4}$ Nanoparticles as Magnetic Resonance Imaging Contrast Agents for Melanoma Tumors. RSC Adv. 2015, 5, 50557-50564.

(33) Rodenas, T.; Luz, I.; Prieto, G.; Seoane, B.; Miro, H.; Corma, A.; Kapteijn, F.; i Xamena, F. X. L.; Gascon, J. Metal-Organic Framework Nanosheets in Polymer Composite Materials for Gas Separation. Nat. Mater. 2015, 14, 48-73.

(34) Shete, M.; Kumar, P.; Bachman, J. E.; Ma, X.; Smith, Z. P.; Xu, W.; Mkhoyan, K. A.; Long, J. R.; Tsapatsis, M. On the Direct Synthesis of $\mathrm{Cu}$ (BDC) MOF Nanosheets and their Performance in Mixed Matrix Membranes. J. Membr. Sci. 2018, 549, 312-320.

(35) Rostamnia, S.; Alamgholiloo, H.; Liu, X. Pd-Grafted Open Metal Site Copper-Benzene-1,4-Dicarboxylate Metal Organic Frameworks (Cu-BDC MOF's) as Promising Interfacial Catalysts for Sustainable Suzuki Coupling. J. Colloid Interface Sci. 2016, 469, 310317.

(36) Buso, D.; Nairn, K. M.; Gimona, M.; Hill, A. J.; Falcaro, P. Fast Synthesis of MOF-5 Microcrystals Using Sol-Gel $\mathrm{SiO}_{2}$ Nanoparticles. Chem. Mater. 2011, 23, 929-934.

(37) Buso, D.; Hill, A. J.; Colson, T.; Whitfield, H. J.; Patelli, A.; Scopece, P.; Doherty, C. M.; Falcaro, P. Complete Characterization of $\alpha$-Hopeite Microparticles: An Ideal Nucleation Seed for Metal Organic Frameworks. Cryst. Growth Des. 2011, 11, 5268-5274.

(38) Sugikawa, K.; Nagata, S.; Furukawa, Y.; Kokado, K.; Sada, K. Stable and Functional Gold Nanorod Composites with A MetalOrganic Framework Crystalline Shell. Chem. Mater. 2013, 25, 25652570.

(39) Yang, T.; Shen, C.; Li, Z.; Zhang, H.; Xiao, C.; Chen, S.; Xu, Z.; Shi, D.; Li, J.; Gao, H. Highly Ordered Self-Assembly with Large Area of $\mathrm{Fe}_{3} \mathrm{O}_{4}$ Nanoparticles and the Magnetic Properties. J. Phys. Chem. $B$ 2005, 109, 23233-23236.

(40) Liu, Z.; Liu, Y.; Yao, K.; Ding, Z.; Tao, J.; Wang, X. Synthesis and Magnetic Properties of $\mathrm{Fe}_{3} \mathrm{O}_{4}$ Nanoparticles. J. Mater. Synth. Process. 2002, 10, 83-87.

(41) Layek, K.; Maheswaran, H.; Arundhathi, R.; Kantam, M. L.; Bhargava, S. K. Nanocrystalline Magnesium Oxide Stabilized Palladium (0): An Efficient Reusable Catalyst for Room Temperature Selective Aerobic Oxidation of Alcohols. Adv. Synth. Catal. 2011, 353, 606-616.

(42) Miyamura, H.; Matsubara, R.; Miyazaki, Y.; Kobayashi, S. Aerobic Oxidation of Alcohols at Room Temperature and Atmospheric Conditions Catalyzed by Reusable Gold Nanoclusters Stabilized by the Benzene Rings of Polystyrene Derivatives. Angew. Chem., Int. Ed. 2007, 46, 4151-4154.

(43) Chen, J.; Zhang, Q.; Wang, Y.; Wan, H. Size-Dependent Catalytic Activity of Supported Palladium Nanoparticles for Aerobic Oxidation of Alcohols. Adv. Synth. Catal. 2008, 350, 453-464.

(44) Wu, H.; Zhang, Q.; Wang, Y. Solvent-Free Aerobic Oxidation of Alcohols Catalyzed by an Efficient and Recyclable Palladium Heterogeneous Catalyst. Adv. Synth. Catal. 2005, 347, 1356-1360.

(45) Choi, K.-M.; Akita, T.; Mizugaki, T.; Ebitani, K.; Kaneda, K. Highly Selective Oxidation of Allylic Alcohols Catalysed by 
Monodispersed 8-Shell Pd Nanoclusters in the Presence of Molecular

Oxygen. New J. Chem. 2003, 27, 324-328.

(46) Chen, G.-J.; Wang, J.-S.; Jin, F.-Z.; Liu, M.-Y.; Zhao, C.-W.; Li, Y.-A.; Dong, Y.-B. Pd@Cu(II)-MOF-Catalyzed Aerobic Oxidation of Benzylic Alcohols in Air with High Conversion and Selectivity. Inorg. Chem. 2016, 55, 3058-3064.

(47) Chen, Y.; Zheng, H.; Guo, Z.; Zhou, C.; Wang, C.; Borgna, A.; Yang, Y. Pd Catalysts Supported on $\mathrm{MnCeO}_{x}$ Mixed Oxides and their Catalytic Application in Solvent-Free Aerobic Oxidation of Benzyl Alcohol: Support Composition and Structure Sensitivity. J. Catal.

2011, 283, 34-44.

(48) Dimitratos, N.; Villa, A.; Wang, D.; Porta, F.; Su, D.; Prati, L. $\mathrm{Pd}$ and Pt Catalysts Modified by Alloying with $\mathrm{Au}$ in the Selective Oxidation of Alcohols. J. Catal. 2006, 244, 113-121.

(49) Proch, S.; Herrmannsdörfer, J.; Kempe, R.; Kern, C.; Jess, A.; Seyfarth, L.; Senker, J. Pt@MOF-177: Synthesis, Room-Temperature Hydrogen Storage and Oxidation Catalysis. Chem. - Eur. J. 2008, 14, 8204-8212.

(50) Dimitratos, N.; Lopez-Sanchez, J. A.; Morgan, D.; Carley, A.; Prati, L.; Hutchings, G. J. Solvent Free Liquid Phase Oxidation of Benzyl Alcohol Using Au Supported Catalysts Prepared Using A Sol Immobilization Technique. Catal. Today 2007, 122, 317-324.

(51) Mitsudome, T.; Noujima, A.; Mizugaki, T.; Jitsukawa, K.; Kaneda, K. Efficient Aerobic Oxidation of Alcohols Using A Hydrotalcite-Supported Gold Nanoparticle Catalyst. Adv. Synth. Catal. 2009, 351, 1890-1896.

(52) Yamaguchi, K.; Mizuno, N. Supported Ruthenium Catalyst for the Heterogeneous Oxidation of Alcohols with Molecular Oxygen. Angew. Chem., Int. Ed. 2002, 41, 4538-4542.

(53) Carson, F.; Agrawal, S.; Gustafsson, M.; Bartoszewicz, A.; Moraga, F.; Zou, X.; Martín-Matute, B. Ruthenium Complexation in An Aluminium Metal-Organic Framework and its Application in Alcohol Oxidation Catalysis. Chem. - Eur. J. 2012, 18, 15337-15344.

(54) Tang, Q.; Huang, X.; Wu, C.; Zhao, P.; Chen, Y.; Yang, Y. Structure and Catalytic Properties of K-Doped Manganese Oxide Supported on Alumina. J. Mol. Catal. A: Chem. 2009, 306, 48-53.

(55) Wang, F.; Ueda, W. Aerobic Oxidation of Alcohols over Novel Crystalline MoVO Oxide. Appl. Catal., A 2008, 346, 155-163.

(56) Kim, B. R.; Oh, J. S.; Kim, J.; Lee, C. Y. Aerobic Oxidation of Alcohols over Copper-containing Metal-Organic Frameworks. Bull. Korean Chem. Soc. 2015, 36, 2799-2800.

(57) Hou, J.; Luan, Y.; Tang, J.; Wensley, A. M.; Yang, M.; Lu, Y. Synthesis of UiO-66- $\mathrm{NH}_{2}$ Derived Heterogeneous Copper (II) Catalyst and Study of its Application in the Selective Aerobic Oxidation of Alcohols. J. Mol. Catal. A Chem. 2015, 407, 53-59.

(58) Hoover, J. M.; Ryland, B. L.; Stahl, S. S. Mechanism of Copper (I)/TEMPO-Catalyzed Aerobic Alcohol Oxidation. J. Am. Chem. Soc. 2013, 135, 2357-2367.

(59) Hoover, J. M.; Stahl, S. S. Highly Practical Copper (I)/TEMPO Catalyst System for Chemoselective Aerobic Oxidation of Primary Alcohols. J. Am. Chem. Soc. 2011, 133, 16901-16910.

(60) Hoover, J. M.; Steves, J. E.; Stahl, S. S. Copper(I)/TEMPOCatalyzed Aerobic Oxidation of Primary Alcohols to Aldehydes with Ambient Air. Nat. Protoc. 2012, 7, 1161.

(61) Hoover, J. M.; Ryland, B. L.; Stahl, S. S. Copper/TEMPOCatalyzed Aerobic Alcohol Oxidation: Mechanistic Assessment of Different Catalyst Systems. ACS Catal. 2013, 3, 2599-2605.

(62) Deng, Y.; Qi, D.; Deng, C.; Zhang, X.; Zhao, D. Superparamagnetic High-Magnetization Microspheres with an $\mathrm{Fe}_{3} \mathrm{O}_{4} @ \mathrm{SiO}_{2}$ Core and Perpendicularly Aligned Mesoporous $\mathrm{SiO}_{2}$ Shell for Removal of Microcystins. J. Am. Chem. Soc. 2008, 130, 28-29.

(63) Carson, C. G.; Hardcastle, K.; Schwartz, J.; Liu, X.; Hoffmann, C.; Gerhardt, R. A.; Tannenbaum, R. Synthesis and Structure Characterization of Copper Terephthalate Metal-Organic Frameworks. Eur. J. Inorg. Chem. 2009, 2009, 2338-2343.

(64) Hummers, W. S. J.; Offeman, R. E. Preparation of Graphitic Oxide. J. Am. Chem. Soc. 1958, 80, 1339. 